\title{
Assessing the Usability of Institutions Web Pages
}

\author{
Saad Subair \\ College of Computer and Information Sciences, Princess Nourah Bint Abdulrahman University, Riyadh, \\ Kingdom of Saudi Arabia \\ Email: sosubair@pnu.edu.sa
}

Received 15 May 2014; revised 20 June 2014; accepted 10 July 2014

Copyright (C) 2014 by author and Scientific Research Publishing Inc.

This work is licensed under the Creative Commons Attribution International License (CC BY).

http://creativecommons.org/licenses/by/4.0/

(c) (i) 0pen Access

\section{Abstract}

The usability of the web pages is assessed using some statistical models. Researchers argue that many usability results and recommendations lack empirical and experimental data. Universities web pages are chosen as subjects for this work. Series of experiments have been conducted to investigate into the usability and design of the universities web pages. Prototype web pages have been developed according to the structured methodologies of web pages design and development. Four universities web pages were evaluated together with the prototype web pages using a questionnaire which was designed according to the Human Computer Interactions (HCI) concepts. The data collected was analyzed using correlation and regression models. The correlation analysis showed that there were significant positive and negative correlations between many items. The regression analysis revealed that the most significant factors (items) that contributed to the best model of the universities web pages design and usability were: multimedia in the web pages, the web pages icons (alone) organization and design, and graphics attractiveness. The results showed some of the limitations of some heuristics used in conventional interface system design and proposed some additional heuristics in web pages design and usability.

\section{Keywords}

Usability, Human Computer Interaction (HCI), User Interface, Regression, Statistical Analysis

\section{Introduction}

User interface is a system layer through which the computer and users communicate [1] [2]. It is an essential part of Human Computer Interaction (HCI). Dealing with or achieving goals using the interface is known as the usability of the interface. Usability of a system is how easy to use the system and how easy and efficiently the 
system performs tasks [3] [4]. In a survey conducted in the last few years, software development devoted almost half (48\%) of the code to the user interface [5] [6]. It is important to devote considerable time, effort, and cost for user interface design and its usability. Usability of the interface is an important issue. Nielsen [4] [7] conducted a usability test for software used by a company. The result concluded that there was a list of 130 usability problem. He concluded that the software design was sound and most of the usability problems were simple enough to fix. As far as usability benefits are concerned, cost saving is considered to be one of the most important benefits of usability. Many researchers [8]-[12] presented several examples of significant cost saving due to usability studies. Usable system leads to training costs, decreased requirement for field support, and increased user satisfaction [13] [14]. The interfaces used in the web pages are graphical user interfaces that utilize graphics, colours, and icons. Researchers showed that there was still a big gap between the researches of the HCI and hypertext systems, essentially the web [15]. Shneiderman [16] argued that many researchers' experience lacked empirical data to validate or solidify their conclusions. Shneiderman [16] reported that web sites could be well categorized by the originator's identity such as individual group, university, corporation and non-profit organization. He concluded that information about users could guide web designers to a better design. However, the problems that motivate this research are:

1) There were no empirical studies that categorized the users of the universities web pages and studied their preference, and the problems they were facing when using these web pages.

2) To specify the relative importance of some items or parameters of interface design and usability.

The main objective of this study is to investigate into the relations between the items of web pages design and their usability and to point out which items or variables contribute significantly to web pages design of the universities. Questionnaires were used to evaluate the usability of interfaces. However, researchers found problems and weaknesses in the questionnaires developed in the past [17] [18]. The problems varied from non-represented population sample, to lack of validation and low reliabilities of the questionnaires. User acceptance or subjective satisfaction of a system was a critical measure of the system success. Chin et al. [19] developed a measurement instrument which measured the user's subjective rating of the human computer interface called the Questionnaire for User Interface Satisfaction (QUIS). Improvements to the questionnaires for evaluating computer systems and interfaces were suggested and introduced by several researchers [20] [21].

\section{Methodology}

In this study, the problems and the objectives of this work which are stated earlier were attempted to be solved through:

1) Designing and developing a prototype user interface for university web pages using recent web pages development methodologies;

2) Evaluating the prototype and other universities web pages usability in a comparative approach through a questionnaire;

3) Using correlation analysis to investigate the relationship and association between items or variables of universities web pages design;

4) Using regression analysis to investigate the causality relationships to find out the most significant independent variables (items) that form the best model or models for the universities web pages design.

The experiment conducted was a comparative evaluation of the usability variables of these web pages. A sample of 60 students was given a questionnaire to respond to. Data of the questionnaire were collected, organized, and saved in a flat file format to be ready to be transferred and manipulated by other packages and programs. SAS and SPSS statistical packages were used to statistically analyze the data. The questionnaire was designed using a rating scale ascending from 1 to 5 which was designed to be administered at controlled experimental conditions. The questions were designed such that each question represents an item of design or heuristic of the interface for the universities web pages. Each item was considered as a variable contributing to the web pages design. In the big experiment of this research, originally several items or variables of web pages design and usability were designed as questions in the questionnaire. In this study only 14 items were considered for the correlation and regression models. They are:

1) Color amount;

2) Contrast against the background;

3) Graphics information provision; 
4) Color and graphics feel of consistency;

5) Navigation;

6) Location tracking inside the web pages;

7) Hyperlinks (hotspot) semantics;

8) Forms organization and helpfulness;

9) Animated pictures effect on web pages look;

10) Text (alone) organization and design;

11) Icons (alone) organization and design;

12) Icons and text organization and design;

13) Multimedia preference;

14) Universities web pages ranking.

\subsection{Correlation Analysis}

Simple correlation between the 14 items of universities web pages design were calculated from the original data. The correlation coefficient $(r)$ between two characters $(X$ and $Y$ ) is usually expressed as follows:

$$
r=\frac{\sum x y}{\sqrt{\left(\sum x^{2}\right)\left(\sum y^{2}\right)}}
$$

where

$$
\begin{aligned}
& x=x-X \text { and, } \\
& y=y-Y \text { and, } \\
& X=\text { Independent variable (item), } \\
& X=\text { is the mean of character } \mathrm{x} . \\
& y=\text { Independent variable (item), } \\
& Y=\text { is the mean of character } \mathrm{y} .
\end{aligned}
$$

\subsection{Regression Analysis}

Simple and multiple linear regressions of some items (independent variables) of the ranking of the university web pages item (dependent variable) were estimated. The formula for multiple linear regressions is given as follows:

$$
Y=a+b_{1} X_{1}+b_{2} X_{2}+\cdots b_{n} X_{n}
$$

where:

$Y=$ dependent variable,

$X_{1-\mathrm{n}}=$ independent variables,

$a=$ intercept of the regression line on the $\mathrm{Y}$ axis,

$b_{1-\mathrm{n}}=$ linear regression coefficients,

$n=$ Number of independent variables.

Backward, forward, and stepwise selection regression analysis had also been attempted. In stepwise selection variables are added (or removed) one by one into (from) the model. The F-statistic is calculated after a variable is added into (or removed from) the model. A variable that did not produce significant F-value at a predefined probability level is then deleted from (or added to) the model. In forward selection, variables already in the model do not necessary stay there and the process ends when none of the variables outside the model is significantly contributing to the model at the specified probability level [21].

\section{Results and Discussion}

The descriptive statistics of the items (variables) designed to investigate the user interface design and usability in this study is calculated. Low variances in the results show continuous data and hence suggest normal distribution of the data. In this paper we will discuss the correlation and regression analysis only.

\subsection{Correlation}

The correlation analysis study is used to explain the relationship between the variables of the web pages design 
and usability. The objective of this model is investigate whatever two variables (items) are related positively or negatively to each other. Table 1 shows the correlation coefficients between the 14 variables studied. The web pages color amount has no significant correlation with any of the variables of the web pages studied. The web pages contrast against the background showed significant positive correlation with the web pages icons and text organization, color and graphics consistency, navigation, location tracking, and forms organization and helpfulness. However, the contrast against the background showed no significant correlation with the web pages animated pictures effect and icons (alone) organization. The web pages graphics information provision has significant positive correlation with all the other variables studied. Specifically, it showed high positive correlation with the web pages hyperlinks semantics (Table 1). Table 1 shows that web pages color and graphics feel of

Table 1. Correlation coefficients of the 14 items (variables) of the universities web pages design and usability.

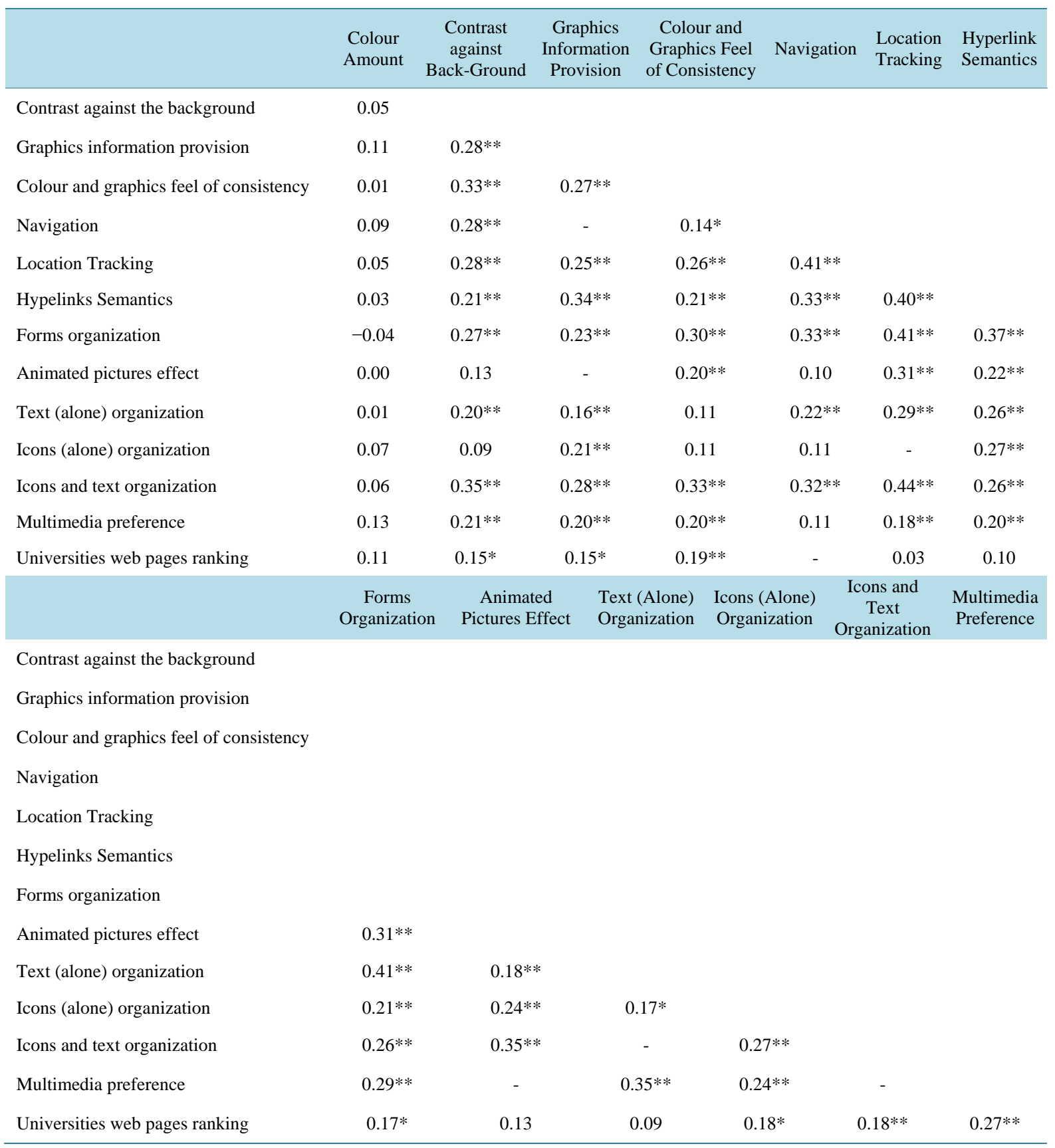

**Significant at 0.05 level of probability. *Significant at 0.10 level of probability. 
consistency has positive significant correlation with most of the variables studied. However, it has no significant correlation with the text (alone) and icons (alone) organization but has high positive significant correlation with the icons and text together organization and helpfulness. Navigation of the web pages has significant positive correlation with all the variables studied except the web pages icons (alone) organization and the multimedia preferences in the universities web pages. Location tracking and hyperlinks semantics showed significant positive correlation (separately) with almost all the other variables studied except the ranking of the universities web pages. This result indicated that the ranking of the web pages of the universities did not rely much on these two variables. The web pages forms organization has significant positive correlation with the rest of the variables studied. Forms organization associated significantly with the ranking of the universities web pages. The animated pictures effect on the web pages showed significant positive correlation with the web pages text (alone), icons (alone), and icons and text (together) organization and helpfulness.

However, animated pictures had no significant correlation with the ranking of the web pages. Text (alone) organization has significant positive correlation with the icons alone organization and multimedia preferences in the web pages of the universities. Text (alone) has no significant correlation with the ranking of the universities web pages. Icons (alone) organization has significant positive correlation with the icons and text (together) organization, multimedia preference, and the web pages ranking. Icons and text (together) organization and multimedia preference had significant positive correlation (separately) with the ranking of the universities pages.

\subsection{Regression}

As mentioned earlier, regression analysis is used to understand how the value of the dependent variable changes when any one of the independent variables is varied. That means regression analysis estimates the conditional anticipation of the dependent variable given the independent variables. Regression analysis is also used to understand which among the independent variables are related to the dependent variable; and to explore the types of these relationships. In some cases, regression analysis can be used to deduce causal relationships between the independent and dependent variables. Here we use the regression model to deduce which independent variable or variables contribute significantly to the dependent variable web pages ranking.

The multiple linear regression results are shown in Table 2. The ANOVA (analysis of variance) table for regression shows that the model was significant at the 0.01 probability level, indicating that the contribution of independent variables coefficients were not equal to zero (alternate hypothesis). Simply, it says that there is a contribution from some variables to the model at a certain level of probability (Table 2). The table clearly shows that multimedia preference in the universities web pages contributed highly and significantly to the model. However, some regression analysis procedures were used, including, forward selection, backward elimination, and stepwise selection. Maximum coefficient of determination $\left(\mathrm{R}^{2}\right)$ was achieved by including specific number of independent variables. The forward selection and backward elimination adds and eliminates (respectively) independent variables to (from) the model regardless of what variables are already outside or existing in the model (tables not shown). Stepwise selection re-examines at every stage the regression of the variables incorporated into the model in previous stages. A variable which might have been the best single variable to enter the model at an early stage, might at later stage, be superfluous because of the relationships between it and other variables now in the regression model [21].

Table 3 further shows a summary of stepwise selection regression procedure model which included only four variables that were significantly contributed to the model at the 0.15 probability level. That is to say, universities web pages multimedia preference, icons (alone) organization, text (alone) organization, and hyperlinks (hotspots) semantics were the four most independent variables contributing to the model significantly.

Coefficient of determination $\left(\mathrm{R}^{2}\right)$ measures the proportion of total sum of squares of the variables that is explained by the regression line (table not shown). It is a measure of how closely the points (observation) fit the least square line. Consequently, the line that has maximum $\mathrm{R}^{2}$ represents the best fitting line [22]. This might indicate the ranking importance of an independent variable as a single or in combination with other independent variables to universities web pages ranking.

The results showed that the universities web pages location tracking, hyperlinks semantics, text (alone) organization, icons (alone) organization, and design, and multimedia preferences were among the first five variables (items) that contributed significantly to the universities web pages ranking model. The limitation to $\mathrm{R}^{2}$ is that the addition of an irrelevant independent variable to the regression model will increase $\mathrm{R}^{2}$ even though 
Table 2. Linear regression analysis of items (variables) of web pages design and usability.

\begin{tabular}{|c|c|c|c|c|c|}
\hline Source & Degrees of Freedom & Sum of Square & Mean Square & $\mathrm{F}$ & $P>F$ \\
\hline Regression & 13 & 70.00086 & 5.384682 & 7.26 & 0.0001 \\
\hline Error & 243 & 180.1159 & 0.741218 & & \\
\hline Total & 256 & 250.1167 & & & \\
\hline Variable & Parameter Estimate & Standard Error & Sum of Squares & $\mathrm{F}$ & $\mathrm{P}>\mathrm{F}$ \\
\hline Intercept & 1.061532 & 0.440591 & 4.302695 & 5.80 & 0.0167 \\
\hline Color amount & 0.027230 & 0.075147 & 0.097328 & 0.13 & 0.7174 \\
\hline Contrast against the background & -0.030090 & 0.059111 & 0.192028 & 0.26 & 0.6112 \\
\hline Graphics information provision & 0.068228 & 0.074656 & 0.619078 & 0.84 & 0.3617 \\
\hline Color and graphics feel of consistency & -0.030560 & 0.071732 & 0.134551 & 0.18 & 0.6704 \\
\hline General navigation & 0.069340 & 0.068237 & 0.765360 & 1.03 & 0.3106 \\
\hline Location Tracking & -0.064310 & 0.069323 & 0.637798 & 0.86 & 0.3545 \\
\hline Hyperlinks (hotspots) semantics & 0.121541 & 0.073557 & 2.023700 & 2.73 & 0.0998 \\
\hline Forms organization and helpfulness & 0.026652 & 0.070631 & 0.105537 & 0.14 & 0.7063 \\
\hline Animated pictures & -0.055670 & 0.089501 & 0.286755 & 0.39 & 0.5345 \\
\hline Text (alone) organization and design & -0.109380 & 0.064121 & 2.157001 & 2.91 & 0.0893 \\
\hline Icons (alone) organization and design & 0.200612 & 0.057933 & 8.888093 & 11.99 & 0.0006 \\
\hline Icons and text organization and design & -0.018650 & 0.060757 & 0.069868 & 0.09 & 0.7591 \\
\hline Multimedia preference & 0.416697 & 0.073722 & 23.68064 & 31.95 & 0.0001 \\
\hline
\end{tabular}

Table 3. Summary of stepwise procedure for dependent variable universities web pages ranking ${ }^{a}$.

\begin{tabular}{ccccc}
\hline Step & Variable Entered/Removed & Number in & Partial R & Model R $^{2}$ \\
\hline 1 & Multimedia preference & 1 & 0.2132 & 0.2132 \\
2 & Icons (alone) organization and design & 2 & 0.0401 & 0.0001 \\
3 & Text (alone) organization and design & 3 & 0.0073 & 0.2534 \\
4 & Hyperlinks semantic & 4 & 0.0094 & 0.2607 \\
\hline
\end{tabular}

$a$ : All variables in the model are significant at 0.15 probability level.

the irrelevant variable is not related to the other variables in the model [22]. The assumption of this model is that all the variables (items) have been estimated precisely. This might not always be true. Overall, the results suggest that, some independent variables significantly contributed to the regression model and others did not. For a single independent variable, multimedia preference of the universities web pages gave the most significant contribution to the dependent variable universities web pages ranking. For two independent variables, icons (alone) organization and design and multimedia preference of the universities web pages gave the most significant contribution to the dependent variable universities web pages ranking. For three independent variables, the universities web pages text (alone) organization and design, icons (alone) organization and design, and multimedia preference gave the most significant contribution to the dependent variable universities web pages ranking.

\section{Conclusion}

Unveiled were important conclusions and findings concerning some items (variables) of the web pages design and usability. These conclusions and findings showed the power of the correlation and regression models to figure out the importance and ranking of the variables that contribute significantly to the usability of the web pages. These models can be applied and extended to any other variables or (items) of web pages design to assess their usability importance. 


\section{Acknowledgements}

The author would like to thank Princess Nourah bint Abdulrahman University, Riyadh, KSA for supporting this research. He also would like to thank all the persons who participated in this research.

\section{References}

[1] Jacko, J.A. (2012) The Human-Computer Interaction Handbook: Fundamentals, Evolving Technologies, and Emerging Applications. CRC Press, Boca Raton, 1518. http://dx.doi.org/10.1201/b11963

[2] Nielsen, J. (1993) Usability Engineering. Academic Press, Boston.

[3] Shneiderman, B., Norman, K., Plaisant, C., Bederson, B., Druin, A. and Golbeck, J. (2013) 30 Years at the University of Maryland's Human-Computer Interaction Lab (HCIL). Interactions, 20, 50-57.

[4] Nielsen, J. (2013) Usability 101: Introduction to Usability. Jakob Nielsen's Alertbox, 25.

[5] Myers, B.A. and Rosson, M.B. (1992) Survey on User Interface Programming. Proceedings of ACM CHI'92 Conference, Monterey, 3-7 May 1992, 195-202.

[6] Norman, D.A. (2010) Natural User Interfaces Are Not Natural. Interactions, 17, 6-10. http://dx.doi.org/10.1145/1744161.1744163

[7] Nielsen, J. (1990) Big Paybacks from “Discount’ Usability Engineering”. IEEE Software 7, 3 May 1990, 107-108.

[8] Davis, P. and Shipman, F. (2011) Learning Usability Assessment Models for Web Sites. Proceedings of the 16th International Conference on Intelligent User Interfaces, New York, 195-204. http://dx.doi.org/10.1145/1943403.1943433

[9] Albert, W., Gribbons, W. and Almadas, J. (2009) Pre-Conscious Assessment of Trust: A Case Study of Financial and Health Care Web Sites. Human Factors and Ergonomics Society Annual Meeting Proceedings, 53, 449453. http://dx.doi.org/10.1177/154193120905300603

[10] Karlin, J.E. and Klemmer, E.T. (1989) An Interview. In: Klemmer, E.T., Ed., Ergonomics: Harness the Power of Human Factors in Your Business. Ablex, Norwood, 197-201.

[11] Bailey, W.A., Knox, S.T. and Lynch, E.R. (1988) Effects of Interface Design Upon User Productivity. Proceedings of ACM CHI'88 Conference. Washington DC, 15-19 May 1988, 207-212.

[12] Karat, C. (1990) Cost-Benefit Analysis of Iterative Usability Testing. Proceedings of the IFIP TC13 3rd Interantional Conference on Human-Computer Interaction, Cambridge, 27-31 August 1990, 351-356.

[13] Landseadel, P. (1994) Methodologies in User Interface Design. IEEE Electronic Library, No. 0-7803-1910-9/94.

[14] Norman, D. and Nielsen, J. (2013) 10 Heuristics for User Interface Design. http://www.nngroup.com/articles/ten-usability-heuristics/

[15] Buckingham, S. and McKnight, C. (1997) Word Wide Web Usability: Introduction to This Special Issue. International Journal of Human-Computer Studies, 47, 1-4. http://dx.doi.org/10.1006/ijhc.1997.0132

[16] Shneiderman, B. (1997) Designing Information-Abundant Web Sites: Issues and Recommendations. International Journal of Human-Computer Studies, 47, 5-29. http://dx.doi.org/10.1006/ijhc.1997.0127

[17] Bailey, J.E. and Person, S.W. (1983) Development of a Tool for Measuring and Analysing Computer User Satisfaction. Management Science, 29, 530-545. http://dx.doi.org/10.1287/mnsc.29.5.530

[18] Larcker, D.F. and Lessig, V.P. (1980) Perceived Usefulness of Information: A psychometric examination. Decision Science, 11, 121-134. http://dx.doi.org/10.1111/j.1540-5915.1980.tb01130.x

[19] Chin, J.P., Virginia, A.D. and Norman, K.L. (1988) Development of an Instrument Measuring User Satisfaction of the Human-Computer Interface. Proceedings of the CHI' 88, ACM. SIGCHI Bulletin. Special Issue ACM Order No. ACM0-89791-265-9/88/0004/0213.

[20] Subair, S. (2014) The Usability Engineering of the Universities Web Pages User Interfaces: A Pragmatic Approach. Princess Nourah Bint Abdulrahamn University Printing Press. Riyadh. (Under Press)

[21] Drapper, N.R. and Smith, H. (1981) Applied Regression Analysis. John Wiley \& Sons Inc., New York.

[22] Retherfor, R.D. and Choe, M.K. (1993) Statistical Models for Causal Analysis. John Wiley \& Sons, Inc., New York. http://dx.doi.org/10.1002/9781118033135 
Scientific Research Publishing (SCIRP) is one of the largest Open Access journal publishers. It is currently publishing more than 200 open access, online, peer-reviewed journals covering a wide range of academic disciplines. SCIRP serves the worldwide academic communities and contributes to the progress and application of science with its publication.

Other selected journals from SCIRP are listed as below. Submit your manuscript to us via either submit@scirp.org or Online Submission Portal.
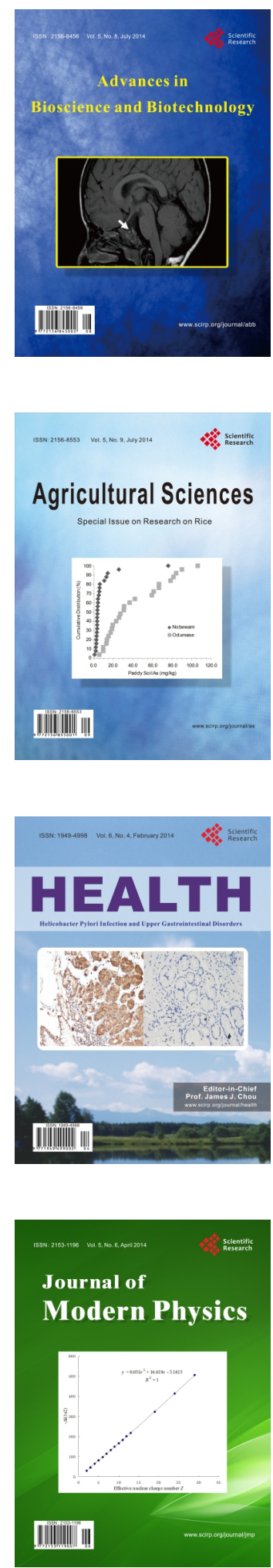
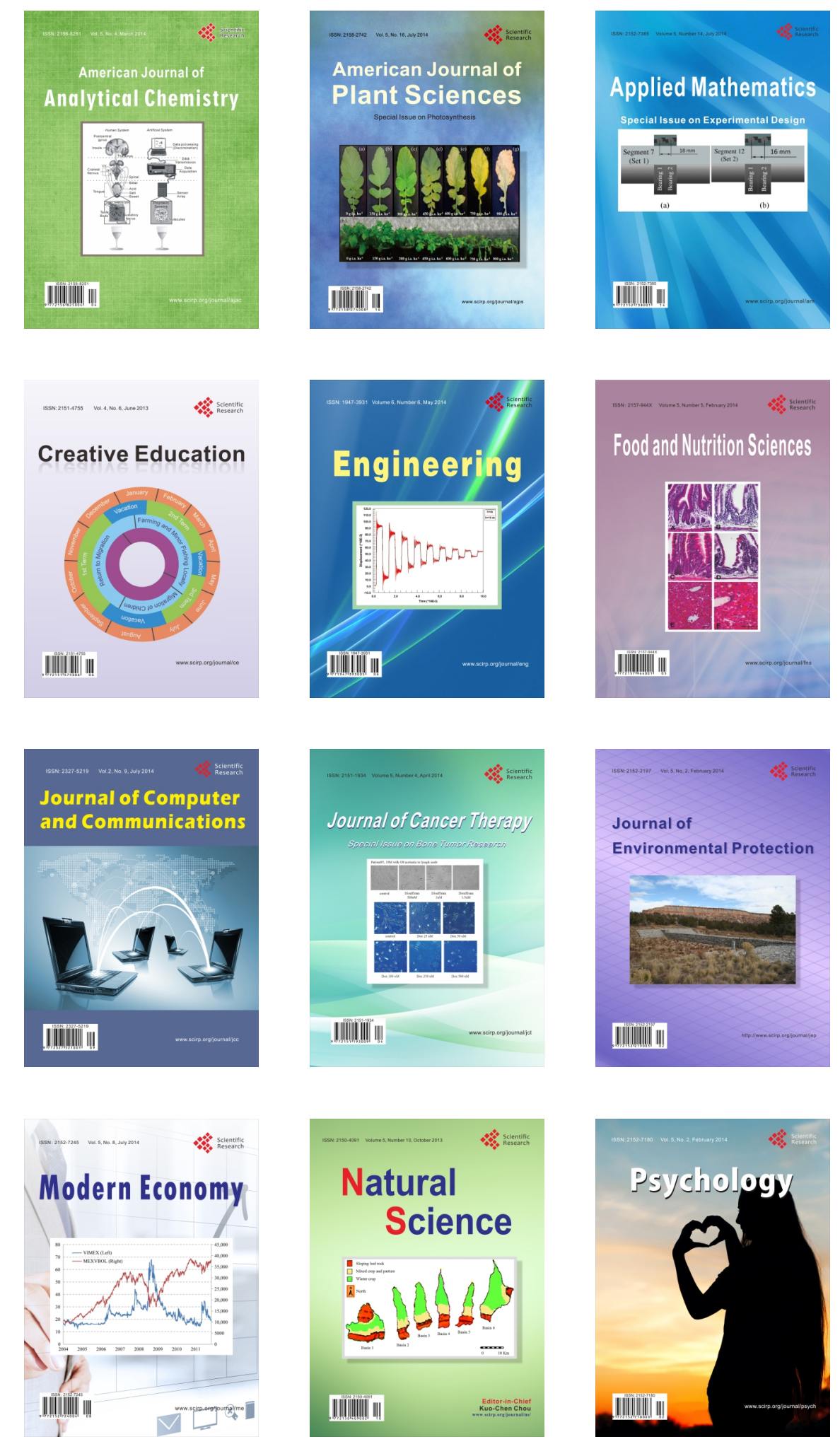